\title{
AFIRMACIONES CONSCIENTEMENTE FALSAS Y MEDIANA DILIGENCIA. A PROPÓSITO DE LA SENTENCIA DE LA CORTE SUPREMA DE FECHA 4 DE ABRIL DE 2016*
}

\author{
IŃIGO DE LA MAZA GAZMURI**
}

\section{1) LOS HECHOS Y LA HISTORIA PROCESAL}

Según consta en el considerando noveno de la sentencia de la Corte Suprema ${ }^{1}$ los hechos de la causa son los siguientes:

a) El 30 de julio de 2008 las partes celebraron un contrato de compraventa respecto del inmueble consistente en departamento A del piso $1^{\circ}$ del edificio ubicado en Hualpén, Avenida La Reconquista $\mathrm{N}^{\circ}$ 8433, lote $\mathrm{N}^{\circ} 1451$ de la población Lan C, Hualpencillo.

b) En la cláusula tercera de la referida convención se pactó el precio en la suma de $\$ 11.636 .899$, que el comprador paga de la siguiente manera: a. Con la suma de $\$ 6.420 .358$ que corresponde al Subsidio Habitacional para la Adquisición de una Vivienda Social, Programa Fondo Solidario de Vivienda I, reglamentado en los artículos $3^{\circ}$ y siguientes del D.S. $\mathrm{N}^{\circ} 174$ (V. y U.) de 2005 . b. Con $\$ 200.636$ provenientes de ahorro enterado por el comprador en su Cuenta de Ahorro a Plazo para la Vivienda $\mathrm{N}^{\circ} 52960506480$, Banco del Estado de Chile, facultando el comprador al vendedor para que en su nombre y representación gire y perciba de dicha cuenta la cantidad de unidades de fomento señalada, por su valor al día de su pago efectivo. c. Con $\$ 1.003 .181$ que corresponden al Subsidio por Superficie a que se refiere el inciso $3^{\circ}$ del artículo $3^{\circ}$ del D.S. $N^{\circ} 174(\mathrm{~V}$. y U.) de 2005. Y d. Con $\$ 4.012 .724$ por el Subsidio Diferenciado a la Localización a que se refiere el artículo 65 bis del D.S. $\mathrm{N}^{\circ} 174$ (V. y U.) de 2005.

En dicha escritura se consigna que "Los referidos subsidios fueron otorgados al comprador por el Servicio de Vivienda y Urbanización Región del Bío-Bío, en virtud de las normas reglamentarias antes citadas”.

Fecha de recepción: 25 de abril de 2016.

Fecha de aceptación: 26 de julio de 2016.

** Abogado; Doctor en Derecho; Profesor Investigador Facultad de Derecho de la Universidad Diego Portales; Profesor de Derecho Civil (CHILE). Correo electrónico: inigo.delamaza@ udp.cl

1 Pedro Valdebenito Saavedra con Lina Fuentes Rojas 
En la misma cláusula el vendedor se obliga a "acompañar toda la documentación exigida para el pago de dichos subsidios por las normas legales y reglamentarias que lo rigen, renunciando desde ya a la acción resolutoria por el no pago de subsidio por incumplimiento de los requisitos previstos para su pago en las respectivas normas legales y reglamentarias"; declara, además, haber recibido la totalidad del precio, y, en consecuencia, estar íntegramente pagado, renunciando ambas partes expresamente a las acciones resolutorias que pudieren emanar del presente contrato.

Por otro lado, en la estipulación $6^{a}$ acordaron que "a fin de dar cumplimiento a lo dispuesto por las normas que regulan el Subsidio del Fondo Solidario de Vivienda I, el comprador constituye prohibición de enajenar la vivienda adquirida en este instrumento durante el plazo de 15 años contados desde la fecha de la inscripción de la prohibición en el Conservador de Bienes Raíces respectivo, sin autorización previa del SERVIU Región del Bío Bío”.

c) La demandada no era beneficiaria de ninguno de los subsidios expresados en el contrato, con los cuales habría pagado el precio de compra del inmueble. Y respecto del valor singularizado en la letra b. de la cláusula tercera no consta que el actor, en uso del mandato conferido en la escritura, haya girado y percibido de dicha cuenta la suma equivalente a 10 UF.

d) El actor no recibió el precio de la compraventa que se consigna en la escritura aludida; no pudo instar por su pago acompañando la documentación exigida para el pago de dichos subsidios; y no consta que haya girado y percibido aquella parte del valor que se dice pagada con el ahorro enterado por la compradora en su Cuenta de Ahorro a Plazo para la Vivienda $N^{\circ}$ 52960506480, Banco del Estado de Chile.

En consideración a estas circunstancias, el vendedor demandó la nulidad del contrato de compraventa por encontrarse su voluntad viciada por dolo. En subsidio, solicitó que se declarara la nulidad del negocio por falta de causa.

A efectos de este comentario, sin embargo, únicamente importa el destino de la demanda por dolo. El tribunal de primera instancia, a través de una sentencia de 29 de enero de $2015^{2}$, desestimó la demanda principal. Apelado el fallo, una sala de la Corte de Apelaciones de Concepción lo confirmó por determinación de ocho de junio de 2015.

El demandante recurrió tanto de casación en la forma como en el fondo. Ambos recursos fueron desestimados por la Corte Suprema. Interesa a este comentario las razones para desestimar la casación en el fondo respecto a la infracción de normas relativas al dolo. 


\section{2) El Razonamiento de la Corte Suprema}

Para considerar el razonamiento de la Corte Suprema convendrá comenzar advirtiendo que, en lo que toca al dolo, la casación en el fondo se enderezó con cargo a infracción de reglas probatorias. De esta manera, en el considerando octavo de la sentencia se lee:

"Conculcación de los artículos 1700, 1702 y 1706 del Código Civil, respecto a la acción principal de nulidad de contrato por consentimiento viciado por dolo, puesto que, sea que el contrato cuya nulidad se busca en el presente juicio conste en un instrumento público o privado, lo cierto es que las declaraciones formuladas hacen plena fe en contra de los contratantes. Esta situación resulta suficiente para tener por acreditado el dolo con que actuó la demandada en la celebración del contrato".

Frente a esto, los juzgadores estimaron, en el considerando decimocuarto de la sentencia lo siguiente:

"Que, en primer lugar, debe repararse en que, para fundar la casación por esta vía el recurrente denuncia preceptos sobre el valor probatorio de la prueba instrumental, sin denunciar las normas que precisamente regulan el dolo, no obstante que esa valoración está vinculada directamente con ese vicio; tanto es así que al estructurar el recurso y al describir cómo se produce la infracción el recurrente va acudiendo al concepto, requisitos y efectos del dolo, y formulando reproches al fallo por esos factores.

A este respecto debe recordarse que, siendo este un recurso extraordinario, sus exigencias son de cumplimiento riguroso. Así, al no ser denunciadas como infringidas las normas pertinentes, en este caso las que regulan el dolo como vicio del consentimiento, en el concepto, su establecimiento como vicio y sus requisitos para configurarlo, debe concluirse que el recurrente se ha conformado con la aplicación que de ellas efectuó el tribunal recurrido, lo cual ya sería suficiente para rechazar el recurso por este capítulo".

Sin embargo, esta no fue la única ni la principal razón por la que desestimaron el recurso de casación en el fondo respecto al dolo. Así parece seguirse de los considerando decimoquinto y decimosexto, que convendrá transcribir a continuación:

"DECIMOQUINTO: Por otra parte, conforme a la definición consignada en el artículo 44 del Código Civil, el dolo es una intención "positiva" de inferir daño. Y hay consenso, en doctrina y jurisprudencia, que la positividad está referida al despliegue de actividades o maniobras dirigidas a concretar aquella intención malsana; así, no basta una pura intención, anidada en la mente, y aun declarada; y aunque fuere declarada en un instrumento público o, por cualquier explicación, indubitado. En estos términos (salvo situaciones muy particulares, entre las que no está el caso), 
una afirmación conscientemente falsa podrá ser signo de mala fe, pero no constituye dolo si el declarante no va más allá de ella; no hay dolo si, controlándose, no avanza al despliegue de actividades o maniobras (entonces llamadas "dolosas") para consumar el engaño, que es lo que conforma el dolo como vicio del consentimiento. En suma, al menos por regla muy general, la sola aserción falsa no basta (en este sentido, entre otros, hay fallos en Revista de Derecho y Jurisprudencia T. 27, secc. $1^{\text {a }}$ p. 440; Revista de Derecho y Jurisprudencia T. 45, secc. $1^{\text {a }}$ p. 568).

La exigencia viene a ensamblar con un mínimo cuidado exigible a todo contratante en la negociación que emprende. Si para un potencial contratante tiene importancia la afirmación que recibe del otro, debe cerciorarse, al menos con mediana diligencia, de la efectividad de lo afirmado, para que más tarde no pueda ser reprochado de que "nadie puede ser oído cuando alega su propia negligencia”.

"DECIMOSEXTO: Que, al aplicar al caso las reflexiones precedentes resulta que, del examen de la sentencia se observa que los hechos relativos a los subsidios fueron establecidos por el fallo recurrido, tal como lo postula el recurrente; entonces, no hay infracción a los preceptos probatorios denunciados; ni a las reglas de los instrumentos públicos (artículos 1700 y 1706 del Código Civil) ni, menos, a la del instrumento privado (artículo 1702 del mismo Código) que han sido denunciadas, por lo que el recurso no puede prosperar por este capítulo.

$Y$ es que la explicación substancial de la insatisfacción del recurrente no debe ser buscada en el valor probatorio de la prueba instrumental. Radica en la configuración de los elementos del dolo. Se puede convenir en que la afirmación de ser titular de los subsidios fue formulada y con toda claridad, que es lo que reclama el recurrente; y también en que fue falsa; pero es que eso no basta como se ha dicho para configurar el dolo.

$\mathrm{Y}$ por eso es que, aunque se llegare a detectar una infracción de las reglas de la valoración de la prueba, dentro de las denunciadas, ese descubrimiento no cambiaría la decisión final, porque aun así, faltando el señalado elemento, no habría dolo. En otros términos, la infracción carecería de influencia substancial en lo dispositivo de la sentencia y el recurso todavía no podría prosperar".

\section{3) LA SITUACIÓN JURÍdICA DE LA AFIRMACIÓN CONSCIENTEMENTE FALSA}

Convendrá comenzar por lo que la Corte estima como la afirmación conscientemente falsa. Se encuentra en el considerando noveno de la sentencia de la Corte Suprema ya citado y es la siguiente: "los referidos subsidios fueron otorgados al comprador por el Servicio de Vivienda y Urbanización Región del Bío-Bío, en virtud de las normas reglamentarias antes citadas." 
En la sentencia se estima que se encuentra acreditado que se trató de una declaración de la compradora. En segundo lugar, no se duda que la afirmación no se correspondía con la realidad y, en tercer lugar, si se presta atención al considerando décimo de la sentencia de la Corte Suprema, se advierte lo siguiente:

"Añaden los jueces que en la diligencia de absolución de posiciones la demandada reconoce que el actor le vendió porque ella le aseguró previamente que contaba con subsidios habitacionales otorgados por el Serviu, con los que le pagaría el precio, pero agrega que al 30 de junio de 2008, fecha de celebración del contrato, tenía aprobado el subsidio según la Egis, lo que le constaba por lo que le dijeron en esa entidad; y así justificada en ausencia de otros elementos de convicción su sola aseveración de ser beneficiaria no constituye una falsedad o mentira propia del elemento material del dolo que se alega".

El párrafo transcrito indica que debe tenerse por acreditado que la compradora no solo conocía la falsedad de su afirmación, sino que, además, la importancia que tenía para el vendedor. Sin embargo, el párrafo en cuestión resulta algo enigmático pues, si bien no cabe duda de que al momento en que se formuló la declaración era falsa, da a entender algo así como que al momento de la celebración del contrato, la afirmación no sería falsa. Sin embargo, este no parece ser el caso pues, como se lee en el considerando noveno de la sentencia de la Corte Suprema relativo a los hechos que deben tenerse por establecidos: "La demandada no era beneficiaria de ninguno de los subsidios expresados en el contrato, con los cuales habría pagado el precio de compra del inmueble." Por otra parte, en la sentencia de primera instancia se lee:

"Ha quedado demostrado, asimismo, con el mérito del Oficio Ord. $N^{\circ} 3856$ del SERVIU Región del Biobio (fs.130) y de la Respuesta Definitiva evacuada por dicho servicio a consulta efectuado en virtud de Ley de Transparencia (fs.84), que la demandada no era beneficiaria de ninguno de los subsidios expresados en el contrato con los cuales habría pagado el precio de compra del inmueble".

En resumen, entonces, en este caso, la compradora formuló una afirmación consciente de su falsedad y de la importancia que tenía para el vendedor.

Nada de eso parece discutirse en la sentencia de la Corte Suprema; lo que, en cambio, se cuestiona es la suficiencia de una afirmación conscientemente falsa para configurar una "maniobra dolosa". En este sentido, en la sentencia de primera instancia se lee: "Que las meras afirmaciones de la compradora de habérsele otorgado los subsidios, no son suficientes a juicio de este sentenciador para acreditar -en el caso sub júdice- el dolo". Por otra parte, convendrá recordar el razonamiento de la Corte:

"...una afirmación conscientemente falsa podrá ser signo de mala fe, pero no constituye dolo si el declarante no va más allá de ella; no hay dolo si, controlándose, no avanza al despliegue de actividades o maniobras (entonces llamadas "dolosas") para consumar el engaño, que es lo que conforma el dolo 
como vicio del consentimiento. En suma, al menos por regla muy general, la sola aserción falsa no basta".

Aquello que la Corte denomina "actividades" o "maniobras" se corresponde con lo que suele considerarse el "elemento objetivo de la conducta dolosa" 3 o la "acción engaños" 4 En este caso, la acción engañosa corresponde a la afirmación conscientemente falsa, y la Corte consideró que no era suficiente para configurar el dolo vicio del consentimiento ¡es este un razonamiento correcto?

Para responder a esta pregunta convendrá desviarse levemente y considerar por algunos momentos la situación del dolo por omisión. Completada esa tarea, se dispondrá de algún material para responder a la pregunta recién planteada.

Suele aceptarse, tanto en el ámbito nacional como en el comparado, que la acción engañosa no solo comprende hechos o circunstancias, sino que, además, omisiones. En este sentido, en el ámbito nacional, Claro Solar señala: "dolo es un acto o una omisión dañoso a otro" 5 . Por su parte, Avelino León indica lo siguiente

"Para provocar el engaño se pueden presentar hechos o circunstancias falsas que alteren la realidad o que coloquen a la victima en la imposibilidad de apreciarla debidamente, en cuyo caso el dolo es positivo. También se puede producir el dolo por omisión; esto es, guardando deliberadamente silencio sobre algún hecho o circunstancia que la otra parte necesite conocer para formarse un juicio verdadero de la realidad"6.

De manera más cauta, Domínguez Águila considera que la definición que suministra el artículo 44 del Código Civil no excluye la posibilidad de que la sola omisión constituya dolo y añade que será el caso cuando exista una obligación de informar y se incumpla deliberadamente para capturar la voluntad negocial de la otra parte . $^{7}$

En el ámbito internacional la literatura es demasiado vasta como para pretender dar siquiera una visión panorámica, sin embargo, para el ámbito español puede considerarse Díez-Picazo y Verda y Rojo Ajuria ${ }^{8}$,

3 Ver, por ejemplo, Verda y Beamonte, José Ramón (2006) “El dolo in contrahendo”. RDP, p. 26 .

4 Flume, Werner (1998) El negocio jurídico, trads. J.M. Miquel González y E. Gómez Calle. Madrid: Fundación Cultural del Notariado, p. 635.

5 Claro Solar, Luis (2013) Explicaciones de derecho civil y comparado, vol. V-2. Santiago: Editorial Jurídica de Chile, p. 201.

6 León Hurtado, Avelino (1979) La voluntad y la capacidad en los actos jurídicos. Santiago: Editorial Jurídica de Chile, p. 205.

7 Domínguez Águila, Ramón (2012) Teoría general del negocio jurídico. Santiago: Editorial Jurídica de Chile, pp. 89-90.

8 Dítz-Picazo, Luis (2007) Fundamentos del derecho civil patrimonial, t. I, Introducción, teoría del contrato, 6a ed. Cizur Menor (Navarra): Thomson Civitas; Rojo Ajuria, Luis (1994) El dolo en los contratos. Madrid: Civitas. 
para el francés, Ghestin y Fabre-Magnan", respecto del alemán, Flume ${ }^{10}$ y del italino, Trabucchi y Bianca ${ }^{11}$. Lo que, en general, muestran las obras citadas son dos cosas. La primera de ellas es que se admite que el dolo pueda configurarse a través de una omisión, la segunda es que no cualquier omisión configura una conducta dolosa, sino que, únicamente aquellas que merecen un reproche especial por resultar contrarias a las exigencias de la buena $\mathrm{fe}^{12}$. Estas dos enseñanzas parecen bien reflejadas en el tratamiento que prodigan los Principios Europeos de Derecho de los Contratos al dolo en su artículo $4.107^{13}$. Su texto es el siguiente:

\section{"Art 4.107. Dolo}

1) Cualquiera de las partes puede impugnar el contrato si este se hubiera concluido en virtud de una representación fraudulenta creada por la otra parte, por medio de sus palabras o de su conducta o como consecuencia de la falta de revelación de información que, de acuerdo con la buena fe y con la equidad, se hubiera debido poner de manifiesto.

2) La representación de la parte o la no revelación de información son fraudulentas si se realiza con el intento de engañar.

3) Para determinar si la buena fe y la lealtad exigen que una parte revele una información concreta deben tomarse en cuenta todas las circunstancias, incluyendo entre ellas:

Si la parte poseía una pericia especial;

El costo de adquisición de la información relevante;

Si la otra parte hubiera podido razonablemente adquirir la información por sí misma; y

La aparente importancia que la información tenía para la otra parte.

Ahora bien, como resulta sencillo advertirlo, el caso que ha originado la sentencia objeto de este comentario no es uno en que exista una omisión, sino una acción ¿por qué, entonces, insistir de esta manera en la

9 Ghestin, Jacques (1993) Traité de droit civil. Les obligations. La formation du contra. París: LGDJ y Fabre-Magnan, Muriel (1992) De l'obligation d'information dans les contrats. Essai d'une théorie. París: LGDJ.

10 Flume (1998) 635-636.

11 Trabucchi, Alberto (1978) Il dolo nella teoria dei vizi del volere. Ristampe, Padua: Edizione Scientifiche Italiane, pp. 526-539 y Bianca, Massimo (2007) Derecho civil, el contrato, trads., F. Hinestrosa y E Cortés. Bogotá: Universidad del Externado.

12 Ambas cosas también pueden extraerse de las fuentes romanas. Ver Zimmermann, Reinhard (1992) The Law of Obligations. Cape Town: Juta \& Co, Ltd.

13 Sobre esto puede consultarse de la Maza Gazmuri, Ińigo (2009) "Buena fe, el reverso de la moneda. A propósito del dolo por omisión y el deber precontractual de informar". Revista Chilena de Derecho Privado, Fernando Fueyo Laneri, No 11, pp. 43-72. 
procedencia del dolo por omisión? La razón es la siguiente. Como se recordará, el fallo de la Corte Suprema señala lo siguiente:

“...una afirmación conscientemente falsa podrá ser signo de mala fe, pero no constituye dolo si el declarante no va más allá de ella; no hay dolo si, controlándose, no avanza al despliegue de actividades o maniobras (entonces llamadas "dolosas") para consumar el engaño".

De esta afirmación pareciere desprenderse que, qua vicio del consentimiento, el dolo requiere de actividades y maniobras del deceptor. Sin embargo, como se ha visto, esta conclusión no se compadece con la comprensión del dolo disponible tanto en derecho nacional como en derecho comparado.

Si esto resulta correcto, entonces, forzosamente, ha de ser incorrecto que el dolo requiera de actividades o maniobras para configurarse como vicio del consentimiento. No puede, jurídicamente, ser esa la razón que aconseje, en este caso, desconocer la existencia de dolo como vicio del consentimiento.

En este caso, ya se ha dicho, existió una conducta de la demandada. La conducta es un engaño consistente en afirmar la existencia de subsidios de los cuales la demandada no era titular. Por lo tanto la pregunta es, más bien, si, qua conducta, ese engaño resulta suficiente para entender que la voluntad del vendedor se encontraba viciada por dolo.

En este sentido, resultará útil considerar la opinión de Bianca, señala este autor lo siguiente:

"El engaño se puede consumar con cualquier medio útil, y así, también con mentiras, que llegarán a conformar el supuesto de hecho doloso si resultan idóneas para influir el consentimiento"14.

Si la opinión de Bianca resulta correcta -y así lo parece- lo importante no es, exactamente, si la maniobra se limitó a una afirmación conscientemente falsa o involucró otras maniobras, sino, más bien si la mentira en que consistió dicha afirmación resultaba idónea para influir en el voluntad del vendedor. En este sentido, prestando atención a la práctica de los tribunales superiores de justicia españoles, Verda y Beamonte considera como casos en ha existido "una infracción grave del principio de la buena fe y de los deberes de lealtad precontractual" 15 y, en consecuencia dolo, los siguientes:

"... los arrendatarios de un local ceden el contrato de arrendamiento, haciendo creer falsamente al cesionario que existía autorización para dicha cesión (...), se concluye un contrato de seguro de construcción, manifestando el constructor que las caracteristicas morfológicas, geológicas y geotécnicas del terreno, en que se asentaba la edificación, eran óptimas, cuando, en realidad,

\footnotetext{
14 Bianca (2007) 687.

15 Verda y Beamonte (2006) 26.
} 
habian existido movimientos o corrimientos de tierra, previos a la contratación del seguro (...); el vendedor de un automóvil afirma que este se encuentra en buen estado, cuando, en verdad, se hallaba en pésimas condiciones, estaba adaptado para minusválidos y «no era apto para el mercado de segunda mano con las minimas garantías" (...); la vendedora de una vivienda, gravada con una hipoteca, consigna expresamente en el contrato que la misma se encuentra libre de cargas (...); se celebra un contrato de reserva de plazas turísticas, asegurándose al cliente que podría disfrutar de dos semanas anuales de vacaciones, entregándosele, con ese fin, una tarjeta que, sin embargo, no le permitió disfrutar de ningún periodo vacacional en establecimiento o complejo vacacional alguno (...); mediante documentos públicos falsos se hace creer que unas minas pueden ser inmediatamente explotadas, cuando, en realidad, no es posible realizar las labores de extracción de minerales, dado que aquellas no son aptas para ser explotadas (...)"16.

Los casos y la consideración de ellos que hace Verda y Beamonte ameritan, al menos, cuatro comentarios. El primero de ellos es que en muchos de ellos parece bastar una mentira para considerar que allí existió dolo. El segundo comentario es que lo que, entonces, resulta relevante es el hecho de que la maniobra haya sido suficiente para captar la voluntad del deceptus. El tercero es que lo reprochable en esa maniobra es, precisamente que constituye una infracción grave a los deberes que impone la buena fe durante el periodo precontractual. En fin, el cuarto comentario surge de uno de los ejemplos pero probablemente pueda extenderse a muchos de los demás. Se trata del caso en que la vendedora de una vivienda, gravada con una hipoteca, consigna expresamente en el contrato que la misma se encuentra libre de cargas. La mentira es evidente, sin embargo, en España, como, por lo demás sucede en Chile, las hipotecas constan en un registro público. Por lo mismo, la pregunta sería ¿̇no debió cerciorarse la compradora de la existencia de dicho gravamen en términos que, de no hacerlo, quedará impedida de alegar el dolo por su propia negligencia?

Quiero detenerme en el tercer y en el cuarto comentario. Me ocuparé del primero de ellos inmediatamente, el segundo será objeto del número siguiente.

Iniciando su tratamiento del dolo como vicio del consentimiento Díez-Picazo afirma lo siguiente:

"Ha señalado nuestra jurisprudencia que, en un sentido muy amplio, dolo es todo complejo de malas artes, contrario a las leyes de la honestidad e idóneo para sorprender la buena fe ajena, generalmente en propio beneficio. Desde este punto de vista, el dolo se asimila a la mala fe y se contrapone a la noción ética de buena fe" ${ }^{\text {"17 }}$.

\footnotetext{
16 Verda y Beamonte (2006) 26-27.

17 Díez-Picazo (2007) 198.
} 
Por su parte, Morales Moreno afirma:

"El carácter ilicito de la conducta debe resultar de la consideración de ella misma (modo en que se manifiesta, medios que utiliza), puesta en relación con las normas del ordenamiento. De estas adquiere en este punto especial relieve el principio de la buena fe. El dolo se considera desde el derecho romano como una conducta contraria a la buena fe ("la buena fe es contraria al fraude y al dolo", ULPIANO, D. 17, 2, 3, 3). La buena fe (lealtad contractual), nos permite concretar o precisar en cada caso los deberes de conducta de los contratantes durante el desarrollo de los tratos y en la celebración del contrato, y, consecuentemente nos determina la existencia de dolo (grave infracción de esos deberes). Las manifestaciones del dolo son tantas como las infracciones de los deberes que impone la buena fe (cfr. P. 7, 16, 1, y siguientes)".

Pues bien, de los comentarios de Díez-Picazo, Morales Moreno y Verda y Beamonte se obtiene que la infracción deliberada de los deberes que impone el principio general de la buena fe equivale a una conducta (incluyendo omisiones) dolosa. Esta idea no solo queda abrigada por la opinión de estos autores, sino que también por una tradición que va desde el derecho romano a las Partidas y cuya influencia aún se deja sentir en el artículo 4:107 de los PECL ¿Se trata de una conclusión extraña para el ámbito nacional? La respuesta es, desde luego que no. Basta considerar la autorizada opinión de Luis Claro Solar, quien señala que: “dolo es toda especie de manobras reprobadas por la buena fe, que una persona emplea para hacer que otra persona incurra en un error que la determine a contratar" 18 .

Siendo las cosas de esta manera, es necesario recordar algún párrafo de la sentencia que, a esta luz, aparece como irremediablemente enigmático: “...una afirmación conscientemente falsa podrá ser signo de mala fe, pero no constituye dolo si el declarante no va más allá de ella”.

¿Qué es, exactamente lo que quiere decirse, que la afirmación conscientemente falsa es un acto de mala fe (entonces, por definición, un incumplimiento de las exigencias más palmarias que impone a las partes el principio general de buena fe mientras negocian) no es un acto doloso?

En otras palabras ¿quiere decir que un atentado a las exigencias de la buena fe, consistente en una declaración destinada a capturar la voluntad de otra persona, no es suficiente para configurar dolo? Pero, entonces, si no es dolo ¿qué es una declaración de mala fe destinada a engañar a otra persona para que contrate?

Quizás, podría afirmarse que no es dolosa porque no consigue su resultado (captar la voluntad de la otra parte), después de todo, como ha señalado Claro Solar: "dolo es toda especie de maniobras reprobadas por la buena fe, que una persona emplea para hacer que otra persona incurra 
en un error que la determine a contratar" ${ }^{19}$. Pero no es una defensa que aquí tenga sentido. Según aparece en la sentencia de la Corte Suprema (considerando primero), existió una absolución de posiciones en la que, en respuesta a una determinada pregunta la demandada "manifiesta que el inmueble que adquirió le fue vendido únicamente por la confianza que tenía en ella el vendedor, por conocerse desde hace muchos años".

Pues bien, es tiempo de recapitular acerca de la situación de la afirmación conscientemente falsa en este caso. Y todo indica que los argumentos que acoge la Corte Suprema para considerar que no configura dolo resultan incorrectos. Como ya se ha visto, resulta irrelevante que no hayan existido más maniobras que una mentira. Se acepta el dolo aun cuando únicamente existe una omisión. Por otra parte, el argumento según el cual es signo de mala fe, pero no alcanza a constituir dolo resulta enigmático ¿qué es lo que diferencia a la mala fe del dolo cuando se trata de una mentira? En realidad, la directa relación entre la infracción a las exigencias de la buena fe y el dolo, lleva a concluir que, correctamente formulado, el argumento parece cortar, precisamente en la dirección inversa: porque la afirmación conscientemente falsa evidencia mala fe es que puede considerarse que ha existido dolo.

Pero, quizás, lo que quiere decir la Corte Suprema es distinto. Probablemente no es que, en abstracto, una declaración deliberadamente falsa no pueda constituir la conducta engańosa que configura el elemento objetivo del dolo, sino que, en concreto, en este caso, aun cuando quedó satisfecho dicho elemento, el caso es que el comprador no podría alegar el dolo pues carece de legitimidad activa para hacerlo y la razón de esta carencia se encuentra en su propia negligencia, consistente en no verificar aquello que la compradora le aseguró.

\section{4) ¿NADIE PUEDE SER OÍDO CUANDO ALEGA SU PROPIA NEGLIGENCIA?}

La plausibilidad de la lectura de la opinión de la Corte Suprema con que concluye el número anterior se desprende del considerando decimosexto de su sentencia, en el cual se señala que existe un mínimo cuidado exigible a todo contratante en la negociación que emprende y que en virtud de ese mínimo cuidado debe cerciorarse con mediana diligencia de la efectividad de lo que se afirmó.

Considerado desaprensivamente el argumento tiene alguna tracción. Después de todo, si se considera que el dolo ha inducido a un error, parece correcto afirmar que ese error debe resultar excusable. Sin embargo, cuando se consideran las cosas con más cuidado, el argumento parece perder su atractivo inicial.

19 Claro Solar (2013) 199. 
Para advertir esto último conviene considerar la excusabilidad como requisito del error invalidante.

En el ámbito nacional, el requisito de la excusabilidad del error puede advertirse ya en Claro Solar, quien, refiriéndose al error obstativo, señala lo siguiente:

"Para que el error obstativo sea juridicamente eficaz, en cuanto a producir el disenso, es necesario que sea excusable, esto es, que no provenga de culpa del que lo alega, o de supina ignorancia suya" 20 .

Por su parte, León Hurtado, se refiere brevemente a la cuestión en los siguientes términos:

"Para que el error vicie el consentimiento, se requiere siempre que se trate de un error excusable (...) Que sea excusable significa en opinión de la doctrina, que el error no provenga de culpa, imprudencia o supina ignorancia de quien lo sufre" 21 .

Con un desarrollo mayor de la idea, Domínguez Águila comienza su tratamiento indicando que la excusabilidad del error sería un precipitado de la máxima nemo auditur y señala lo siguiente:

"Esta norma de moral (...) tiene también aplicación en materia de error. En efecto, por todos se exige, para que el error llegue a viciar el consentimiento, en todas las hipótesis vistas un elemento fundamental: que sea excusable, esto es que no provenga de culpa del que lo alega, o de imprudencia o supina ignorancia suya. Pues si el error se debe a quien lo alega y no tomó la más minima precaución para asegurarse de lo que estaba haciendo, no puede pedir protección y ampararse en su falta para exigir la nulidad del negocio"22.

Más adelante indica que:

"Esta exigencia de excusabilidad del error no puede sujetarse a normas objetivas y debe apreciarse en cada caso, teniendo en cuenta la calidad y condición del que alega el error, su capacidad personal de apreciar condiciones del acto, su carácter profesional o no, su experiencia y capacidad personal, Por ello, será más exigente el deber impuesto a la parte de informarse, si es profesional respecto de la materia a que el negocio se refiere" 23 .

Luego, a diferencia de los otros autores citados, presta atención a la naturaleza recíproca del problema, en los siguientes términos:

"...la exigencia de la excusabilidad del error permite abordar el problema de la justa distribución del riesgo en la contratación, usando el criterio ético que implica juzgar si el error es o no excusable. En efecto, si solo hubiera que atenerse a la consideración de la recta formación de la voluntad, en verdad todo error, desde que determina la formación de la voluntad, debería incidir en su validez (...) pero en los negocios bilaterales esa sola consideración

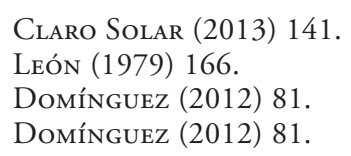


conduciría no solamente a la extrema inseguridad comercial, sino además a injusticias, porque también ha de considerarse el interés de la contraparte que, en los más de los casos, ninguna influencia ha tenido en aquel error y que ha confiado en la celebración del negocio. La nulidad por error ha de balancear entonces los intereses en presencia y distribuir los riesgos en que incurren ambas partes y uno de los medios de decidir a favor de uno u otro de estos intereses es, justamente, el principio nemo auditur aplicado a la doctrina del error" 24 .

El examen de Domínguez Águila resulta especialmente lúcido y, considerado con atención, enseña por qué no se puede trasplantar sin más el requisito de la excusabilidad del error al dolo.

La razón consiste en que, cuando se piensa, con suficiente detenimiento, el requisito de la excusabilidad del error se aprende que no se trata de una sanción al contratante negligente, sino de una protección al otro contratante que confió en la declaración de quien había padecido un error que, sin embargo, era derrotable a través del ejercicio de cierta diligencia. De lo que se trata, entonces, es de comparar las conductas de ambas partes y determinar quién merece mayor protección del ordenamiento jurídico ${ }^{25}$.

Sin embargo, esa comparación de las conductas que, tratándose del error, aconseja proteger a quien confió en la declaración de voluntad y no en quien, negligentemente, padeció un error, no conduce en el mismo sentido tratándose del dolo. Rojo Ajuria ha expresado las cosas con especial claridad:

"El conflicto de intereses, la razón de la tutela jurídica, que justifica el requisito de la excusabilidad en el error, la protección de un contratante que legitimamente ha confiado en la validez del contrato, no se reproducirá en el supuesto del dolo"26.

Como puede verse, entonces, la Corte Suprema hace un uso del nemo auditur que tiene pleno sentido tratándose del error, pero no del dolo, porque si se aplicara tratándose de este último se produciría una situación jurídicamente repugnante: se protegería a quien se comportó dolosamente en perjuicio de quien se comportó culpablemente.

Ahora bien, eso, por supuesto, no significa que el dolo permita anular un contrato cuando el error que se alega resulta extremadamente grosero, pero la razón no es precisamente la excusabilidad del error. Si una persona alega que fue inducido a un error de esta naturaleza, la cuestión será más bien que el tribunal debería fallar que dicho error no se encuen-

\footnotetext{
24 Domínguez (2012) 82.

25 He explorado con cuidado esta idea en De la Maza Gazmuri, Iñigo (2016) "La naturaleza recíproca del problema: a propósito de la excusabilidad del error". Prensa con Homenaje al profesor Enrique Barros Bourie. 
tra acreditado; en otras palabras -y como lo ha decidido, al menos en un par de ocasiones, el Tribunal Supremo Español- la decisión del Tribunal debería ser que no se ha acreditado que se produjo el engaño que se alega para justificar el dolo ${ }^{27}$.

No parece, sin embargo, que esta sea la situación en el caso que resolvió la sentencia de la Corte Suprema. En ningún momento señala el Tribunal dudas respecto al hecho de que el comprador haya sido genuinamente engańado. Lo que señala más bien es que si se hubiera comportado diligentemente hubiera podido derrotar el engaño. Como ya se ha visto, la conclusión no resulta correcta. Corresponde a un trasplante demasiado apresurado de la disciplina del error.

Estas últimas ideas respecto al nemo auditur se formulan asumiendo que el vendedor fue negligente, sin embargo, probablemente, convenga preguntarse si el hecho de que el vendedor no haya comprobado la efectividad de los subsidios puede calificarse jurídicamente como negligencia.

Señala la Corte Suprema que el comprador debió haber empleado una mediana diligencia para verificar las declaraciones de la vendedora. Algo semejante ha decidido la Corte Suprema en otra sentencia anterior de 9 de septiembre de 2014, referida esta vez a la compraventa de unas pertenencias mineras que se ofrecieron sin hipotecas ni gravámenes ${ }^{28}$. En esa ocasión, y refiriéndose a una excepción de contrato no cumplido interpuesta por la vendedora quien alegaba incumplimiento pues las pertenencias estaban gravadas con una hipoteca, la Corte Suprema tuvo por correcto el razonamiento de la Corte de Apelaciones de La Serena:

"Es más, si, con todo, fuese efectivo el desconocimiento que alega el comprador demandado, aquel se debería a una negligencia grave de su parte que no resulta excusable desde el punto de vista jurídico, tal como el propio legislador se encarga de establecer en el artículo 1858 regla $3^{a}$ del Código Civil".

La negligencia consistiría en no haber consultado los registros públicos en que constaba la hipoteca. Después de todo, la compradora debió haber consultado dichos registros.

Sin embargo, en otra sentencia, esta vez de 30 de mayo de $2001^{29}$, la Corte Suprema, conociendo de una demanda de nulidad absoluta por error obstáculo, parece haber considerado las cosas de manera diversa.

El Tribunal de primera instancia declaró la nulidad absoluta de la venta por error esencial ${ }^{30}$. Conociendo del recurso de apelación, la Corte de Apelaciones de Temuco revocó el fallo. Este segundo tribunal estimó

\footnotetext{
27 Ver Morales Moreno, Antonio Manuel (1993) “Comentario artículos 1.269 y 1.270”. Comentarios al Código Civil y compilaciones forales, Albaladejo, M. y Alabart, S. (dir.), t. XVII, vol. 1-B. Madrid: Edersa, p. 386.

28 Empresa Minera Oriel Gerardo y Cía. Ltda. con Comercial Minera San Cristóbal Ltda (2014).

29 José Ortelio García Pinilla con Nelson Albornoz Ruedlinger (2001)

30 Tribunal, 11/3/98, rol 28593, cita online CL/JUR/1093/1998
} 
que no existía error, sino una venta de cosa ajena) y, obiter dicta, se refirió a la excusabilidad del error, en los siguientes términos:

"Que tan cierto es que los subastadores conocieron las bases de la subasta y que por tanto supieron o al menos estuvieron en posibilidad de conocer que el ejecutado no era exclusivo dueño del inmueble, sino conjuntamente y en comunidad con su hermano que en la demanda expresan que el error esencial consistió en que en las publicaciones correspondientes... se señalaba a los interesados que se vendia una propiedad como especie o cuerpo cierto..., lo cual no se indicaba en las publicaciones, sino precisamente en las bases".

Este razonamiento no persuadió a la Corte Suprema, que, conociendo de un recurso de casación en el fondo estimó la existencia de un error esencial y, específicamente en el tema de la excusabilidad, estimó lo siguiente:

"Que en la especie, de acuerdo con los presupuestos fácticos resumidos en el considerando segundo, los demandantes, fundadamente creyeron adquirir el dominio pleno sobre el inmueble ubicado en Portales $N^{o} 361$ de Temuco, en circunstancias que se trataba de la venta de una cuota equivalente al 50\% de dicho derecho de dominio, desde que en las bases de remate se indicó que se vendia el inmueble e igual cosa sucedió en las publicaciones de los avisos respectivos. Si bien es efectivo que se señalaba en las bases la inscripción conservatoria del inmueble, donde fácilmente los demandantes pudieron averiguar exactamente lo que se enajenaba, no lo es menos el que esta venta se realizó a través de un procedimiento judicial de cumplimiento forzado de una obligación, donde la oferta de venta, materializada en las bases de remate y en la publicación de los avisos, está avalada por el órgano jurisdiccional, de suerte que si se dice vender el bien raiz referido, los demandantes, racional y fundadamente, creyeron estar comprando la propiedad plena de la cosa y no una cuota de aquella".

Esta última sentencia de la Corte Suprema parece razonar de una manera diversa a la de la pertenencia minera y a la de la venta que se está comentando. A diferencia de estas dos últimas, su énfasis no parece encontrarse en si la información resultaba o no sencillamente accesible, sino en una cuestión distinta y es la confianza que podía tener quien recibió la información en que esta fuera correcta. Lo que pareciera seguirse de la sentencia de la compra de derechos sobre un inmueble es algo así como el deber de informarse comienza allí donde termina la confianza razonable.

Pues bien ¿resultaba razonable en este caso creer en lo que la vendedora afirmaba respecto de los subsidios? La respuesta, en mi opinión es que sí. Salvo que las partes deban asumir que las declaraciones deliberadamente falsas se encuentran protegidas por el Derecho, todo indica que se puede confiar en que quien afirma algo cuya veracidad debería constarle (es el caso del otorgamiento de los subsidios) está diciendo la verdad. A este respecto, quizás convenga tener presente que, aún un derecho de 
contratos tan extremadamente atento a la posición adversarial de las partes como el inglés, en el cual se ha llegado a sostener que las exigencias de la buena fe son "inherentemente repugnantes" al carácter adversarial de la negociación de un contrato ${ }^{31}$, responsabiliza a quien, incluso sin ánimo de engañar, formula declaraciones falsas ${ }^{32}$.

Como sea que fuere, aunque no se comparta esta última conclusión y se estime que el comprador fue negligente, la respuesta respecto a la existencia de dolo por parte de la compradora es la misma. La compradora se comportó dolosamente al mentir y, en la medida en que su maniobra fue suficiente para inducir a error al comprador en términos que, de haber sabido la verdad no hubiera contratado, esa maniobra es suficiente para anular el contrato por dolo. No obsta a esta conclusión que se considere negligente la conducta del comprador pues, ya ha quedado dicho, la excusabilidad del error no tiene espacio en el dolo como determinante de la legitimidad activa del deceptus para solicitar la nulidad del negocio.

$\mathrm{Si}$ estas conclusiones son correctas, entonces, forzosamente, no lo es la sentencia de la Corte Suprema.

31 La expresión pertenece a LORD ACKNER, la formuló en su decisión de Walford v Miles, un caso resuelto por la House of Lords en el ańo 1992. El párrafo completo es el siguiente:

"el concepto de un deber de negociar un contrato de buena fe resulta inherentemente repugnante a la posición adversarial de las partes que se encuentran negociando un contrato. Cada una de las partes está facultada para perseguir su propio interés mientras evite incurrir en misrepresentations. Para procurar este interés las partes deben estar facultadas, si lo consideran apropiado, a amenazar con retirarse de la negociación o, de hecho, a retirarse con el objetivo de que la otra parte busque reabrir la negociación ofreciéndole mejores condiciones".

32 Sobre misrepresentation puede consultarse Cartwright, John (2007) Misrepresentation, Mistake and Non-Disclosure. Londres: Sweet \& Maxwell, pp. 1-377. 